\title{
De gedecentraliseerde integratie van het sociale domein
}

\author{
Duco Bannink, Hans Bosselaar, Judith van der Veer \& Willem Trommel
}

Het debat over centrale en decentrale verantwoordelijkheden voor sociaal beleid en over de integratie of specialisatie van de verschillende functies van het sociale beleid is al zeker een eeuw oud. De Armenwet van 1912 reguleerde enigszins het armenbeleid dat in Nederland op lokaal niveau gevoerd werd. $\mathrm{Na}$ de Tweede Wereldoorlog ontstond een strijd tussen twee concepties van lokaal sociaal beleid (Rigter e.a., 1995). Het toenmalige ministerie van Cultuur, Recreatie en Maatschappelijk Werk was voorstander van een conceptie die zorg en inkomen in samenhang zag. Het ministerie van Sociale Zaken zag de lokale sociale voorzieningen als een verlengstuk van het domein van werk en inkomen. Sociale Zaken won en de Bijstandswet van 1965 werd daarmee een centraal gestuurde maar decentraal uitgevoerde inkomensvoorziening. Daarnaast ontstond - ook centraal gestuurd - een stelsel van sociale en langdurige zorg dat zich min of meer los van de bijstandsvoorziening ontwikkelde. De eerste eeuw van strijd om de organisatie van het sociale domein eindigde met twee naast elkaar bestaande, centraal gestuurde maar decentraal uitgevoerde subdomeinen.

Met de financiële krapte van de jaren tachtig ontstond op deze inrichting van het systeem een dubbele reactie. De ene helft van de reactie is te vatten in het idee van 'belang en beleid' (Wetenschappelijke Raad voor het Regeringsbeleid, 1994): de kosten van het sociale beleid zijn onbeheersbaar omdat 'belang' en 'beleid' niet zijn verbonden. Daar waar verantwoordelijkheden worden gedragen, moeten de risico's worden gevoeld. Als het 'belang' decentraal ligt, kun je de kosten van het beleid beheersen. Dit idee is ook van toepassing verklaard op de individuele burger. De burger moet worden 'geactiveerd' om zelf ook bij te dragen aan de oplossing van zijn of haar problemen. De tweede helft van de reactie richt zich op de verkokering van het veld. Op het niveau van de casus (de wijk, de cliënt) hangen verschillende deelproblematieken samen. De institutionele scheiding van de beleidsdomeinen maakt het in de praktijk welhaast onmogelijk om de multiproblematiek van burgers effectief en doelmatig aan te pakken De integratie van beleidsvelden op het lokale niveau (waar de multiproblematiek op casusniveau goed is vast te stellen) leidt tot een effectievere aanpak van sociale problemen.

De dubbele kritiek op de inrichting van het systeem biedt ook een oplossingsrichting: decentralisatie van belang en integratie van beleid. Het is deze dubbele aanpak die centraal staat in het decentralisatiebeleid dat de afgelopen jaren is

* Dr. Duco Bannink is universitair hoofddocent bestuurswetenschappen aan de Vrije Universiteit Amsterdam. E-mail: d.b.d.bannink@vu.nl. Hans Bosselaar is academic manager Governance of Activation aan de Vrije Universiteit Amsterdam. Judith van der Veer is onderzoeker Governance of Activation aan de Vrije Universiteit Amsterdam. Prof. dr. Willem Trommel is hoogleraar bestuurswetenschappen aan de Vrije Universiteit Amsterdam. 


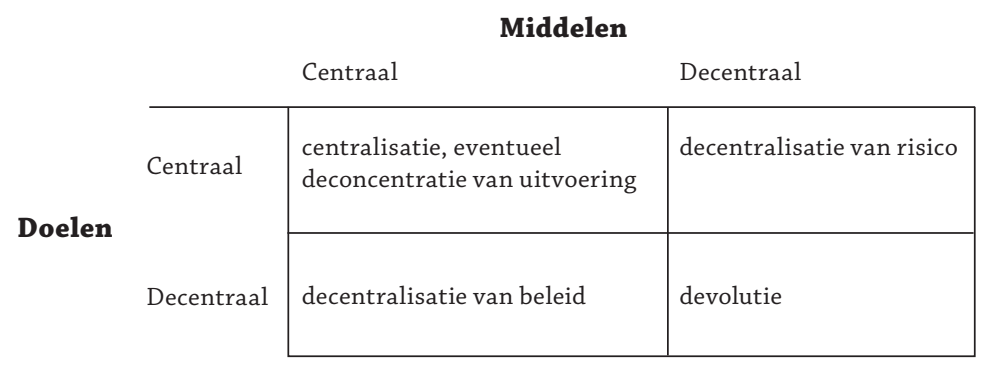

Figuur 1. Governance-verhoudingen

ingezet in het sociale domein. Succes is echter niet verzekerd. In dit artikel laten we zien dat beide oplossingsrichtingen niet goed op elkaar passen (zie ook Bannink, Bosselaar \& Van der Veer, 2013).

\section{Decentralisatie van belang: de WWB}

De nieuwe Algemene Bijstandswet (nAbw) van 1996 en de Wet Werk en bijstand (WWB) van 2004 zetten vooral in op de decentralisatie van het belang.

Beleid, volgens de klassieke definitie van Hoogerwerf (onder meer Hoogerwerf, 2003), is een samenstel van doeleinden en middelen, in bepaalde tijdskeuzen. Middelen en doelen kunnen beide onafhankelijk van elkaar, ofwel op centraal of op decentraal niveau liggen. Als we de tijdskeuzen in het midden laten, kan beleid in vier verschillende 'governance-verhoudingen' bestaan (zie figuur 1).

'Doelen' verwijst hier naar de beleidsinhoud. De verschuiving van de beleidsinhoud naar decentraal niveau betekent dat aan decentraal niveau de bevoegdheid wordt gegeven of gelaten om beleid te formuleren.

'Middelen' verwijst naar budgetten en andere hulpbronnen. Maar wat betekent het precies als middelen worden gedecentraliseerd? Het betekent uiteraard niet dat gemeenten over een ongelimiteerde hoeveelheid middelen kunnen beschikken, integendeel. Het betekent dat er weliswaar een budget wordt verstrekt door de nationale overheid, maar dat het gebruik van die middelen voor risico is van de decentrale overheid. Als het budget op een effectieve manier wordt aangewend, blijft er geld over dat de lokale overheid ergens anders voor kan gebruiken. Als het gebruik van diezelfde middelen ineffectief gebeurt, blijft er niks over en heeft de decentrale overheid pech. Dit betekent - welbeschouwd - het decentraliseren van het risico van succes en falen van de beleidsuitvoering.

De belangrijkste vraag is nu hoe zo'n budget de effectiviteit van het beleid definieert. Hoe dichter de vormgeving van het budget centrale beleidsdoelstellingen volgt, hoe meer de decentralisatie van middelen interfereert met de decentralisatie van de beleidsinhoud. Stel dat de gemeente in een beleidsdomein - laten we zeggen openbare orde - inhoudelijke beleidsvrijheid krijgt, maar stel daarnaast dat het budget wordt gebaseerd op het aantal verstrekte verkeersboetes, dan 
wordt via de vormgeving van het budget gedefinieerd wat effectief beleid is en daarmee wat de onderliggende beleidsdoelstelling is. In dit geval wordt in het beleidsdomein 'openbare orde' de centrale doelstelling gespecificeerd als verkeersveiligheid.

In de WWB zien we dat de beleidsmiddelen inderdaad zijn verschoven. Het risico van succes en falen van de beleidsuitvoering is bij de gemeente gelegd. Dit gebeurde in de WWB via de constructie van het zogenaamde inkomensdeel of 'I-deel' van het budget. Dit is het deel van het WWB-budget dat voor risico van de decentrale uitvoerder van het beleid komt. Dit deel van het budget dekt de vooraf geschatte kosten van de uitkeringsverstrekking. De vormgeving van dit budget sluit zo een definitie van succes en falen van beleid en daarmee een definitie van de centrale doelstelling van het beleid in: succes is winst op het I-deel; falen is een tekort (als de gemeente veel uitstroom realiseert, houdt zij over op het vooraf geschatte budget). We zien hier dat - zoals in het hierboven gegeven voorbeeld over openbare orde - een specifieke beleidsdoelstelling in het budget is opgenomen. Gemeentelijk bijstandsbeleid moet niet primair gericht zijn op inkomensondersteuning, of op de ondersteuning van de maatschappelijke participatie van burgers die slecht in het eigen inkomen kunnen voorzien. Primair moet het gemeentelijke beleid gericht zijn op de minimalisering van de uitgaven aan bijstandsuitkeringen.

Het risico van beleidsfalen en -succes is gedecentraliseerd, waarbij de vormgeving van het budget een specifieke doelstelling suggereert (minimalisering van het inkomensdeel). Het I-deel van het budget werd aangevuld met een W-deel. Het W-deel werd op declaratiebasis verstrekt (dus de verstrekking volgt de daadwerkelijke uitgaven, precies omgekeerd aan het I-deel; niet de gemeente, maar het Rijk draagt hier het risico). Het W-deel was bestemd voor uitgaven die de gemeente doet ten behoeve van de re-integratie van cliënten. In het I-deel voelt de gemeente een prikkel om de uitgaven aan uitkeringen te minimaliseren. Deze prikkel wordt versterkt in het W-deel, dat de gemeente gratis geld ter beschikking stelt voor de re-integratie van cliënten. De vormgeving van het $\mathrm{W}$-deel deed wel inbreuk op de systematiek van de wet, want er werden allerlei voorwaarden aan de aanwending gesteld. Het ging er vooral om dat minder kansrijke groepen cliënten niet werden uitgesloten van het re-integratiebeleid.

De WWB is een vorm van prikkelsturing door de centrale overheid. $\mathrm{Na}$ de WWB-evaluatie van 2007 (Bosselaar e.a., 2007) werd dit nog versterkt. In de aanbiedingsbrief van de staatssecretaris (Kamerstukken II, 2007-2008 en appendix) en in een debat met de permanente parlementaire commissie Sociale Zaken (Kamerstukken II, 2007-2008) kwam de problematiek van de re-integratie van moeilijke cliënten naar voren. In een brief aan het parlement uit 2009 (Kamerstukken II, 2009-2010) wordt betoogd dat gemeenten in staat gesteld moeten worden om hun aanpak van verschillende typen cliënten te differentiëren. Deze lijn werd ook gevolgd in het Plan van Aanpak Reïntegratie uit 2007 (Kamerstukken II, 2008-2009, bijlage 1) en het Bestuursakkoord Samen aan de Slag van de VNG en het ministerie uit 2007 (Kamerstukken II, 2007). Afgesproken werd dat gemeenten re-integratie-instrumenten mogen toedelen aan die groepen in het 
cliëntenbestand die het meest in staat zijn om effectief van de middelen gebruik te maken.

Vervolgens werd een welbeschouwd logische gevolgtrekking daarvan gemaakt in de vormgeving van het $\mathrm{W}$-deel van het budget. Dit gebeurde in twee stappen in de periode vanaf 2009. Nu aanvaard was dat de decentrale beleidsuitvoerder (de gemeente) in staat moest zijn om zelf te kiezen op welke cliënten re-integratieinstrumenten moesten worden gericht en wat voor instrumenten moesten worden toegepast, werden in 2009 verschillende budgetten die raakvlakken vertoonden met de versterking van arbeidscapaciteiten samengevoegd. Het nieuwe 'participatiebudget' sloot de bestaande budgetten voor re-integratie, inburgering en volwasseneneducatie in (Kamerstukken II, 2008-2009, p. 82). In de begroting van dat jaar werd de tweede logische gevolgtrekking, de beperking van de omvang van de re-integratiemiddelen, al aangekondigd:

'Met het tegelijkertijd met deze begroting aan de Tweede Kamer aangeboden Plan van Aanpak re-integratie geeft het kabinet inzicht in de wijze waarop het kabinet beoogt de inzet van re-integratiemiddelen meer vraaggericht en selectiever in te zetten. Dit moet bijdragen aan de verbetering van de resultaten van re-integratie.' (Kamerstukken II, 2008-2009, p. 81)

Het voornemen om de resultaten te verbeteren door de selectiviteit van de toepassing van de middelen te vergroten, is gebaseerd op het inzicht dat de decentrale beleidsuitvoerder (de gemeente) tot op heden niet had kunnen kiezen. De niet-selectieve aanwending van middelen hangt samen met de beperkte resultaten. Met andere woorden, de bestaande vergoedingen voor re-integratie-instrumenten zijn deels ineffectief. Althans, ineffectief als je redeneert vanuit de onveranderd in de vormgeving van het budget gedefinieerde centrale doelstelling van het WWB-beleid: minimalisering van uitkeringslasten door maximalisering van uitstroom en preventie. De effectiviteit van de aangewende re-integratiemiddelen is vanzelf lager als je voorschrijft dat die middelen ook moeten worden aangewend voor moeilijke doelgroepen in het cliëntenbestand. Aan de bovenkant van het cliëntenbestand zijn de middelen overbodig; aan de onderkant van het cliëntenbestand leidt het aanbieden van voorzieningen niet tot het beoogde effect, althans niet tot uitstroom, dus niet tot rendement in termen van het I-deel. Selectieve toepassing van middelen voor de middengroep is in die redenering het meest effectief.

In de begroting van 2011 en in sterkere mate in die van 2012 is, in navolging van het Plan van Aanpak Reïntegratie 2007, het Bestuursakkoord Samen aan de Slag van 2009 en de aankondiging in de begroting van 2009, een beperking van het re-integratiebudget doorgevoerd (zie tabel 1).

We zien een WWB ontstaan waarin het principe van 'gedecentraliseerd belang' in steeds sterkere mate is doorgevoerd. De gemeente wordt gezien als de bestuurslaag die de effectiviteit van re-integratiebeleid kan bepalen, en daarom draagt de gemeente het risico van de uitkeringskosten van de bijstand. De vormgeving van het budget definieert een centrale prestatie: hoe zwaarder het risico van de uitke- 
Tabel 1. Ontwikkeling participatiebudget (uitgaven aan gemeenten, bestaande uit flexibel re-integratiebudget, inburgering WWI, educatie OCW; in miljarden euro's), 2010-2013, in begrotingen 2011 en 2012 (Kamerstukken II, 2010-2011, p. 96, Kamerstukken II, 2011-2012, p. 92 en de toelichting op de post Participatiebudget op p. 93)

\begin{tabular}{lllll}
\hline Participatiebudget & $\mathbf{2 0 I 0}$ & $\mathbf{2 0 I I}$ & $\mathbf{2 0 I 2}$ & $\mathbf{2 0 1 3}$ \\
\hline begroting 20II & $€ \mathrm{I}, 89$ & $€ \mathrm{I}, 70$ & $€ \mathrm{I}, 40$ & $€ \mathrm{I}, 32$ \\
begroting 2012 & $€ \mathrm{I}, 90$ & $€ \mathrm{I}, 70$ & $€ 0,99$ & $€ 0,72^{\prime}$ \\
\hline
\end{tabular}

ringskosten op de gemeente drukt, hoe meer de gemeente daadwerkelijk moet inzetten op een beleid dat gericht is op de directe uitstroom van bijstandsontvangers.

\section{Decentraal, integraal zorgbeleid: de WMO}

Voordat we in de volgende paragraaf de integratie van sociale inkomensvoorziening en sociale zorg bespreken (in de 'drie decentralisaties'), moeten we ingaan op de governance-verhoudingen in het domein van de sociale zorg. De sociale zorg is met de WMO van 2007 gedecentraliseerd naar gemeenten, maar de governanceverhouding in de WMO is anders dan die in de WWB.

Bij de WMO gaat het om inzet op maatschappelijke participatie en om verschillende doelgroepen (niet alleen om het beëindigen van de uitkeringskosten van bijstandsontvangers). De WMO bestaat uit negen prestatievelden. De middelen voor dat beleid zijn naar de gemeenten verschoven. Gemeenten moeten zorgen dat burgers een afdoende mate van ondersteuning ondervinden op die negen prestatievelden, maar dit betekent niet noodzakelijkerwijs dat er op alle velden een voorziening wordt aangeboden. Er wordt een budget geboden waarvan de centrale overheid verwacht dat het afdoende zal zijn om tegemoet te komen aan de behoefte aan maatschappelijke ondersteuning in de gemeente, maar er is geen specifieke invulling voorgeschreven in het beleid, noch in de vormgeving van het budget.

Hierbij kent de WMO een heel eigen provisielogica (Van der Veer, 2013, 20). De ontwikkeling daarvan is te zien in de wijziging van terminologie die het ministerie in de jaren voorafgaand aan de indiening van de WMO hanteerde. In 2003 (Kamerstukken II, 2003-2004) sprak het kabinet over de Wet Maatschappelijke Zorg. In de contourennota van 2004 (Kamerstukken II, 2003-2004) wordt inmiddels gesproken van de Wet Maatschappelijke Ondersteuning. Deze terminologie onderstreept het brede karakter van de wet, zo schrijft de staatssecretaris (p. 3). De aangekondigde WMO streeft niet langer naar het integreren van de zorgvoorzieningen op lokaal niveau, maar streeft ook naar zelfwerkzaamheid en burgerparticipatie in de maatschappelijke zorg.

Er wordt daarbij een 'drieslag' (Kamerstukken II, 2003-2004, p. 2) aangekondigd van zelfwerkzaamheid, ondersteuning waar die zelfwerkzaamheid niet vanzelf van de grond komt (dit is het beoogde domein van de WMO), en zorgvoorziening 
voor ernstige gevallen van zorgbehoefte die zich niet lenen voor maatschappelijke zorg (dit blijft het domein van de Algemene Wet Bijzondere Ziektekosten). In de wet werd deze drieslag verder uitgewerkt in het zogenaamde 'compensatieprincipe' (artikel 4 WMO):

'1. Ter compensatie van de beperkingen die een persoon als bedoeld in artikel 1, eerste lid, onder g, onderdeel 4,5 en 6 , ondervindt in zijn zelfredzaamheid en zijn maatschappelijke participatie, treft het college van burgemeester en wethouders voorzieningen op het gebied van maatschappelijke ondersteuning die hem in staat stellen:

a. een huishouden te voeren;

b. zich te verplaatsen in en om de woning;

c. zich lokaal te verplaatsen per vervoermiddel;

d. medemensen te ontmoeten en op basis daarvan sociale verbanden aan te gaan.

2. Bij het bepalen van de voorzieningen houdt het college van burgemeester en wethouders rekening met de persoonskenmerken en behoeften van de aanvrager van de voorzieningen, alsmede met de capaciteit van de aanvrager om uit een oogpunt van kosten zelf in maatregelen te voorzien.'

Dit compensatieprincipe stond niet in het wetsvoorstel en was een compromis tussen politieke partijen die streefden naar lokale beleidsruimte en politieke partijen die twijfels hadden of die lokale beleidsruimte afdoende waarborg voor de toegang tot zorg zou bieden (Van der Veer, 2013, 25). Met de formulering van het compensatieprincipe is een compromis gevonden waarin de wet niet aan gemeenten voorschrijft welke voorzieningen zij moeten aanbieden, maar wel de problematiek waarop de maatschappelijke ondersteuning zich moet richten definieert: het ondersteunen van de vier aspecten van zelfredzaamheid.

Deze terughoudende positie van de nationale overheid over de invulling van de beleidsinhoud is ook zichtbaar in de governance-verhouding van de WMO. De definitie van het centrale governance-mechanisme van de WMO in een brief over de voorbereiding van de WMO uit november 2004 luidt (Kamerstukken II, 2004-2005, p. 1): 'De vormgeving van het WMO beleid dient plaats te vinden op lokaal niveau in de plaatselijke democratie. Daarvoor is noodzakelijk dat gemeenten voldoende vrijheid en een adequaat instrumentarium hebben.' Deze 'horizontale verantwoording' maakt deel uit van de WMO. Anders dan in de WWB schept de WMO geen set prikkels gericht op het produceren van een centraal gedefinieerde prestatie, maar wordt een sociaal probleem gedefinieerd, en wordt als randvoorwaarde voor de aanpak ervan een procedure voorgeschreven.

Anders dan de WWB is de WMO dan ook te zien als een voorbeeld van devolutie van beleid. Zowel de beleidsrisico's als de beleidsinhoud zijn verschoven naar de gemeente. Het financiële arrangement van de WMO schrijft niet een bepaalde prestatie voor. De beleidsinhoud wordt binnen de gemeente, in een horizontale verhouding, bepaald. En inderdaad draagt de gemeente de kosten voor de uitvoering van dit beleid. 


\section{Integratie van beleid: van WWB en WMO naar de 'drie decentralisaties'}

De WMO definieert een 'sociaal probleem' en een methode van aanpak (horizontale verantwoording); de WWB introduceert een financieringssystematiek (het I-deel) gericht op het decentraal behalen van een centraal gedefinieerde 'prestatie.'

We keren nu even terug naar de WWB. De 'gedecentraliseerd belang'-conceptie van de WWB leidt tot het in het budget definiëren van een 'prestatie'. Met de bezuinigingen op het participatiebudget wordt selectie van cliënten noodzakelijk om uit te komen met het budget. Het gaat hier om selectie op basis van verwacht rendement in termen van het I-deel, dus op een beleid dat maximaal is gericht op re-integratie van cliënten. Een triagemodel van selectie van cliënten voor ondersteuning bij de re-integratie ligt voor de hand. Dat betekent: help de middengroep; de bovengroep redt zichzelf; de ondergroep is verloren moeite.

Terwijl de vormgeving van het budget nog steeds maximaal inzet op re-integratie, is het participatiebudget tegelijkertijd een verbreding van het domein van cliënten en beleidsvelden. Want het participatiebudget is niet alleen een beperking van de hoeveelheid middelen, maar ook de integratie van een aantal andere op participatie gerichte budgetten. Het participatiebudget sluit immers oude, op maatschappelijke participatie gerichte budgetten in. Niet de uitstroom naar werk, maar het versterken van maatschappelijke participatie is de centrale doelstelling van het participatiebudget. Hier blijkt de financieringssystematiek in strijd met de inhoudelijke doelstelling: de financieringssystematiek dwingt tot verdere versmalling op de gedefinieerde prestatie (uitstroom); de inhoudelijke doelstelling vraagt om verbreding.

Wat werkt sterker door? De prestatiegerichte dwang van de financiering? Of het bredere, probleemgerichte verzoek tot verbreding van de doelstelling?

Hier begint het veld van de sociale inkomensvoorziening sterk te raken aan het veld van de sociale zorg. Het participatiebudget was een belangrijke integratiestap, maar in de nabije toekomst worden de beleidsdomeinen van de sociale inkomensvoorziening en de sociale zorg verder geïntegreerd. Dit is het proces van de 'drie decentralisaties' waarover op dit moment van alles te doen is.

Bij de 'drie decentralisaties' zal het budget dat beschikbaar is voor de maatschappelijke zorg worden samengevoegd met het oude (maar in een vorige fase dus al verbrede) participatiebudget. Er komt een nieuw, nog breder participatiebudget waaruit zowel de maatschappelijke zorg als de ondersteuning bij re-integratie betaald moet worden. De bedoeling is om hiermee samenhang te creëren tussen die subdomeinen van het sociale beleid.

Het is niet per se waar dat maatschappelijke zorg en re-integratie elkaar wederzijds kunnen versterken. In één gezin zou de aanpak van werkloosheid moeten samenhangen met de aanpak van zorgbehoevendheid, en die weer met de aanpak van jeugd- en gezinsproblematiek. Maar de taken en doelstellingen van de verschillende organisaties die meehelpen bij zo'n gezin passen niet op elkaar.

Dit wordt nog eens versterkt door de manier waarop 'decentraal belang' en 'integratie van beleid' worden gecombineerd. Weliswaar worden de gemeentelijke budgetten voor zorg en participatie samengevoegd, maar er is ook de op re-integratie 
gerichte prikkel van de WWB en die prikkel blijft na de 'drie decentralisaties' bestaan. Gemeenten mogen zelf hun beleid inrichten op het verbrede veld van zorg en participatie, zeker. Maar cynisch gezegd kost zorg alleen maar geld, terwijl re-integratie geld kan opleveren.

Voor de gemeente geldt: het gebruik van het participatiebudget voor maatschappelijke zorg gaat ten koste van de beschikbare middelen voor zorg en participatie, terwijl re-integratie van een uitkeringsgerechtigde geld kan opleveren (besparing op het I-deel). Hier bestaat volgens ons een belangrijk gevaar. Het is te verwachten dat er een zekere trek is naar gemeentelijk beleid dat vooral inzet op snel te realiseren arbeidsparticipatie. De WMO heeft een precair maar behoorlijk functionerend systeem geschapen van horizontaal gestuurde sociale zorg, met een echte gemeentelijke budgettaire verantwoordelijkheid voor de aanpak van een in de eigen gemeente gedefinieerde sociale problematiek. De WWB heeft een robuust systeem geschapen waarin de aandacht van gemeenten via het opleggen van een specifiek budgettair risico wordt gericht op een centraal gedefinieerde prestatie. Het lijkt ons de vraag of de precaire verhoudingen van de WMO overeind kunnen blijven onder de robuuste druk van de WWB.

\section{Noot}

1 De samenstelling van het participatiebudget in de begroting van 2012 verschilt van die in de vorige begroting. In het participatiebudget van de begroting van 2012 zijn ook de middelen voor de Wet sociale werkvoorziening en de in afbouw zijnde middelen voor re-integratie van Wajong-cliënten opgenomen (Divosa, Factsheet gevolgen miljoenennota 2012 voor Participatiebudget, 11 september 2011, p. 2). Het bedrag van $€ 2,36$ miljard dat is begroot voor 2012 loopt terug naar nul in 2013 (Kamerstukken II, $33000 \mathrm{XV}, 2$, p. 103). Als we dit bedrag aftrekken van de $€ 3,08$ miljard die in de begroting van 2012 is opgenomen voor het gewijzigde participatiebudget, dan resteert een bedrag van $€ 0,72$ miljard.

\section{Literatuur}

Bannink, D., Bosselaar, H., \& Veer, J. van der (2013). Do Local Landscapes Emerge? Reflecting on Local Welfare Crafting in the Netherlands. In: D. Bannink, H. Bosselaar \& W. Trommel (Eds.), Crafting local welfare landscapes. Den Haag: Eleven, 141-154.

Bosselaar, H., Bannink, D., Deursen, C. van, \& Trommel, W. (2007). Werkt de WWB? Resultaten van de ontwikkeling van nieuwe verhoudingen tussen Rijk en gemeenten. Den Haag: Ministerie van Sociale Zaken en Werkgelegenheid.

Hoogerwerf, A. (2003) Beleid, processen en effecten. In: A. Hoogerwerf \& M. Herweijer (red.), Overheidsbeleid. Een inleiding in de beleidswetenschap. Alphen aan den Rijn: Kluwer, 17-36.

Rigter, D., Bosch, E. van den, Veen, R. van der, \& Hemerijck, A. (1995). Tussen sociale wil en werkelijkheid. Een geschiedenis van het beleid van het ministerie van Sociale Zaken. Den Haag: VUGA Uitgeverij. 
Veer, J. vander (2013). Weg uit het verleden. Een institutionele analyse van de gemeentelijke uitwerking van de Wet maatschappelijke ondersteuning (Wmo). Amsterdam: VU University Press.

Wetenschappelijke Raad voor het Regeringsbeleid (1994). Belang en beleid. Naar een verantwoorde uitvoering van de werknemersverzekeringen. Den Haag: Sdu Uitgeverij. 